\title{
Approximate Solution of Two-Dimensional Nonlinear Wave Equation by Optimal Homotopy Asymptotic Method
}

\author{
H. Ullah, ${ }^{1}$ S. Islam, ${ }^{1}$ L. C. C. Dennis, ${ }^{2}$ T. N. Abdelhameed, ${ }^{3,4}$ I. Khan, ${ }^{3}$ and M. Fiza ${ }^{1}$ \\ ${ }^{1}$ Department of Mathematics, Abdul Wali Khan University Mardan, Mardan 23200, Pakistan \\ ${ }^{2}$ Department of Fundamental and Applied Sciences, Universiti Teknologi PETRONAS, 31750 Perak, Malaysia \\ ${ }^{3}$ College of Engineering Majmaah University, Majmaah, Saudi Arabia \\ ${ }^{4}$ Mathematics Department, Faculty of Science, Beni-Suef University, Beni-Suef, Egypt
}

Correspondence should be addressed to L. C. C. Dennis; dennis.ling@petronas.com.my

Received 2 October 2014; Revised 17 December 2014; Accepted 18 December 2014

Academic Editor: Haranath Kar

Copyright (C) 2015 H. Ullah et al. This is an open access article distributed under the Creative Commons Attribution License, which permits unrestricted use, distribution, and reproduction in any medium, provided the original work is properly cited.

The two-dimensional nonlinear wave equations are considered. Solution to the problem is approximated by using optimal homotopy asymptotic method (OHAM). The residual and convergence of the proposed method to nonlinear wave equation are presented through graphs. The resultant analytic series solution of the two-dimensional nonlinear wave equation shows the effectiveness of the proposed method. The comparison of results has been made with the existing results available in the literature.

\section{Introduction}

The wave equations play a vital role in diverse areas of engineering, physics, and scientific applications. An enormous amount of research work is already available in the study of wave equations $[1,2]$. This paper deals with the twodimensional nonlinear wave equation of the form

$$
\frac{\partial^{2} u(x, t)}{\partial t^{2}}-u(x, t) \frac{\partial^{2} u(x, t)}{\partial x^{2}}=1-\frac{x^{2}+t^{2}}{2}, \quad 0 \leq x, t \leq 1 .
$$

The differential equations (DEs) can be solved analytically by a number of perturbation techniques $[3,4]$. These techniques are fairly simple in calculating the solutions, but their limitations are based on the assumption of small parameters. Therefore, the researchers are on the go for some new techniques to overcome these limitations.

The idea of homotopy was pooled with perturbation. Liao [5] proposed homotopy analysis method (HAM) in his $\mathrm{Ph} . \mathrm{D}$. dissertation and applied it to various nonlinear engineering problems [6-8]. The homotopy perturbation method (HPM) was initially introduced by $\mathrm{He}$ [9-13]. HPM has been extensively used by several researchers successfully for physical models [14-16]. Some useful comparisons between HAM and HPM were done by Domairry and Liang $[17,18]$.

Recently Marinca and Herișanu [19-21] introduced OHAM for the solution of nonlinear problems which made the perturbation methods independent of the assumption of small parameters, and Ullah et al. [22-26] have extended and applied OHAM successfully for numerous nonlinear phenomena.

The motive of this paper is to apply OHAM for the solution of two-dimensional nonlinear wave equations. In [19-21] OHAM has been proved to be useful for obtaining an approximate solution of nonlinear differential equations. Here, we have proved that OHAM is more useful and reliable for the solution of two-dimensional nonlinear wave equations, hence, showing its validity and greater potential for the solution of transient physical phenomenon in science and engineering.

Section 2 has the basic idea of OHAM formulated for the solution of partial differential equations. In Section 3, the effectiveness of OHAM for two-dimensional nonlinear wave equation has been studied. 


\section{Basic Formulation of OHAM}

Consider the partial differential equation of the following form:

$$
\begin{gathered}
\mathscr{A}(u(x, t))+f(x, t)=0, \quad x \in \Omega \\
\mathscr{B}\left(u, \frac{\partial u}{\partial x}\right)=0, \quad x \in \Gamma,
\end{gathered}
$$

where $\mathscr{A}$ is a differential operator, $u(x, t)$ is an unknown function, $x$ and $t$ denote spatial and temporal independent variables, respectively, $\Gamma$ is the boundary of $\Omega$, and $f(x, t)$ is a known analytic function. $\mathscr{A}$ can be divided into two parts: $\mathscr{L}$ and $\mathcal{N}$ such that

$$
\mathscr{A}=\mathscr{L}+\mathscr{N}
$$

where $\mathscr{L}$ is the simpler part of the partial differential equation which is easier to solve and $\mathcal{N}$ contains the remaining part of $\mathscr{A}$.

According to OHAM, one can construct an optimal homotopy $\phi(x, t ; p): \Omega \times[0,1] \rightarrow \mathfrak{R}$ which satisfies

$$
\begin{aligned}
H(\phi(x, t ; p), p)= & (1-p)\{\mathscr{L}(\phi(x, t ; p))+f(x, t)\} \\
& -H(p)\{\mathscr{A}(\phi(x, t ; p))+f(x, t)\}=0 .
\end{aligned}
$$

Here the auxiliary function $H(p)$ is nonzero for $p \neq 0$ and $H(0)=0$. Equation (4) is called optimal homotopy equation. Clearly, we have

$$
\begin{aligned}
p=0 \Longrightarrow H(\phi(x, t ; 0), 0)=\mathscr{L}(\phi(x, t ; 0))+f(x, t)=0 & \\
p=1 & \Longrightarrow H(\phi(x, t ; 1), 1) \\
& =H(1)\{\mathscr{A}(\phi(x, t ; 1))+f(x, t)\}=0 .
\end{aligned}
$$

Obviously, when $p=0$ and $p=1$ we obtain $\phi(x, t ; 0)=$ $u_{0}(x, t)$ and $\phi(x, t ; 1)=u(x, t)$, respectively. Thus, as $p$ varies from 0 to 1 , the solution $\phi(x, t ; p)$ approaches from $u_{0}(x, t)$ to $u(x, t)$, where $u_{0}(x, t)$ is obtained from (4) for $p=0$ :

$$
\mathscr{L}\left(u_{0}(x, t)\right)+f(x, t)=0, \quad \mathscr{B}\left(u_{0}, \frac{\partial u_{0}}{\partial x}\right)=0 .
$$

Next, we choose auxiliary function $H(p)$ in the form

$$
H(p)=p C_{1}+p^{2} C_{2}+\cdots+p^{m} C_{m} .
$$

To get an approximate solution, we expand $\phi\left(x, t ; p, C_{i}\right)$ by Taylor's series about $p$ in the following manner:

$$
\phi\left(x, t ; p, C_{i}\right)=u_{0}(x, t)+\sum_{k=1}^{\infty} u_{k}\left(x, t ; C_{i}\right) p^{k}, \quad i=1,2, \ldots
$$

Substituting (8) into (4) and equating the coefficient of like powers of $p$, we obtain zeroth-order problem, given by (6), the first- and second-order problems are given by (9) and (10), respectively, and the general governing equations for $u_{k}(x, t)$ are given by (11) as follows:

$$
\begin{aligned}
& \mathscr{L}\left(u_{1}(x, t)\right)=C_{1} \mathcal{N}_{0}\left(u_{0}(x, t)\right), \quad \mathscr{B}\left(u_{1}, \frac{\partial u_{1}}{\partial x}\right)=0 \\
& \mathscr{L}\left(u_{2}(x, t)\right)-\mathscr{L}\left(u_{1}(x, t)\right) \\
& =C_{2} \mathcal{N}_{0}\left(u_{0}(x, t)\right) \\
& \quad+C_{1}\left[\mathscr{L}\left(u_{1}(x, t)\right)+\mathscr{N}_{1}\left(u_{0}(x, t), u_{1}(x, t)\right)\right], \\
& \qquad \mathscr{B}\left(u_{2}, \frac{\partial u_{2}}{\partial x}\right)=0, \\
& \mathscr{L}\left(u_{k}(x, t)\right)-\mathscr{L}\left(u_{k-1}(x, t)\right) \\
& =C_{k} \mathcal{N}_{0}\left(u_{0}(x, t)\right) \\
& \quad+\sum_{i=1}^{k-1} C_{i}\left[\mathscr{L}\left(u_{k-i}(x, t)\right)\right. \\
& \left.+\mathcal{N}_{k-i}\left(u_{0}(x, t), u_{1}(x, t), \ldots, u_{k-i}(x, t)\right)\right] \\
& k=2,3, \ldots, \\
& \mathscr{B}\left(u_{k}, \frac{\partial u_{k}}{\partial x}\right)=0,
\end{aligned}
$$

where $\mathcal{N}_{k-i}\left(u_{0}(x, t), u_{1}(x, t), \ldots, u_{k-i}(x, t)\right)$ are the coefficient of $p^{k-i}$ in the expansion of $\mathcal{N}(\phi(x, t ; p))$ about the embedding parameter $p$. One has

$$
\begin{aligned}
\mathcal{N}\left(\phi\left(x, t ; p, C_{i}\right)\right)= & \mathcal{N}_{0}\left(u_{0}(x, t)\right) \\
& +\sum_{k \geq 1} \mathcal{N}_{k}\left(u_{0}, u_{1}, u_{2}, \ldots, u_{k}\right) p^{k}
\end{aligned}
$$

It should be underscored that the $u_{k}$ for $k \geq 0$ is governed by the linear equations with linear boundary conditions that come from the original problem, which can be easily solved.

It has been observed that the convergence of the series equation (8) depends on the auxiliary constants $C_{1}, C_{2}, \ldots$ If it is convergent at $p=1$, one has

$$
\widetilde{u}\left(x, t ; C_{i}\right)=u_{0}(x, t)+\sum_{k \geq 1} u_{k}\left(x, t ; C_{i}\right) .
$$

Substituting (13) into (1), it results in the following expression for residual:

$$
R\left(x, t ; C_{i}\right)=\mathscr{L}\left(\widetilde{u}\left(x, t ; C_{i}\right)\right)+f(x, t)+\mathscr{N}\left(\widetilde{u}\left(x, t ; C_{i}\right)\right) .
$$

In actual computation $k=1,2,3, \ldots, m$. If $R\left(x, t ; C_{i}\right)=0$ then $\tilde{u}\left(x, t ; C_{i}\right)$ is the Exact solution of the problem. Generally it does not happen, especially in nonlinear problems.

For determining auxiliary constants, $C_{i}, i=1,2, \ldots, m$, there are a number of methods like Galerkin's method, 
Ritz method, least squares method, and collocation method. The method of least squares can be applied as follows:

$$
\begin{gathered}
J\left(C_{i}\right)=\int_{0}^{t} \int_{\Omega} R^{2}\left(x, t ; C_{i}\right) d x d t \\
\frac{\partial J}{\partial C_{1}}=\frac{\partial J}{\partial C_{2}}=\cdots=\frac{\partial J}{\partial C_{m}}=0 .
\end{gathered}
$$

The $m$ th-order approximate solution can be obtained by these optimal constants. The more general auxiliary function $H(p)$ is useful for convergence, which depends on constants $C_{1}, C_{2}, \ldots, C_{m}$, can be optimally identified by (16), and is useful in error minimization.

\section{Application of OHAM to Two-Dimensional Nonlinear Wave Equations}

To demonstrate the effectiveness of the formulation of OHAM, we consider two-dimensional nonlinear wave equations of the form (1) with initial conditions

$$
u(0, t)=\frac{t^{2}}{2}, \quad \frac{\partial}{\partial x} u(0, t)=0 .
$$

Applying the method formulated in Section 2 leads to

$$
\begin{gathered}
\mathscr{L}=\frac{\partial^{2} u(x, t)}{\partial x^{2}}, \quad \mathcal{N}=-u(x, t) \frac{\partial^{2} u(x, t)}{\partial t^{2}}, \\
f(x, t)=1-\frac{x^{2}+t^{2}}{2} .
\end{gathered}
$$

Zeroth-Order Problem. Consider

$$
\begin{gathered}
\frac{\partial u_{0}(x, t)}{\partial t}=1-\frac{x^{2}+t^{2}}{2}, \\
u_{0}(0, t)=\frac{t^{2}}{2}, \quad \frac{\partial}{\partial x} u_{0}(0, t)=0 .
\end{gathered}
$$

Its solution is

$$
u_{0}(x, t)=\frac{x^{2}}{2}+\frac{t^{2}}{2}-\frac{x^{2} t^{2}}{4}-\frac{x^{4}}{24} .
$$

First-Order Problem. Consider

$$
\begin{aligned}
\frac{\partial^{2} u_{1}(x, t)}{\partial x^{2}}= & \left(1+C_{1}\right) \frac{\partial^{2} u_{0}(x, t)}{\partial x^{2}}-C_{1} u_{0}(x, t) \frac{\partial^{2} u_{0}(x, t)}{\partial t^{2}} \\
& +\left(1+C_{1}\right)\left(\frac{x^{2}}{2}+\frac{t^{2}}{2}-1\right) \\
& u_{1}(0, t)=0, \quad \frac{\partial}{\partial x} u_{1}(0, t)=0 .
\end{aligned}
$$

Its solution is

$$
u_{1}(x, t)=\left(-\frac{1}{4} t^{2} x^{2}-\frac{x^{2}}{24}+\frac{t^{2} x^{4}}{24}+\frac{7 x^{6}}{720}-\frac{x^{8}}{2688}\right) C_{1}
$$

Second-Order Problem. Consider

$$
\begin{aligned}
& \frac{\partial^{2} u_{2}(x, t)}{\partial x^{2}} \\
& =\left[\left(1+C_{1}\right) \frac{\partial^{2} u_{1}(x, t)}{\partial x^{2}}+C_{2} \frac{\partial^{2} u_{0}(x, t)}{\partial x^{2}}\right. \\
& \quad-C_{1} u_{0}(x, t) \frac{\partial^{2} u_{1}(x, t)}{\partial t^{2}}-C_{1} u_{1}(x, t) \frac{\partial^{2} u_{0}(x, t)}{\partial t^{2}} \\
& \left.\quad-C_{2} u_{0}(x, t) \frac{\partial^{2} u_{0}(x, t)}{\partial t^{2}}+C_{2}\left(\frac{x^{2}}{2}+\frac{t^{2}}{2}-1\right)\right], \\
& u_{2}(0, t)=0, \quad \frac{\partial}{\partial x} u_{2}(0, t)=0 .
\end{aligned}
$$

Its solution is

$$
\begin{aligned}
& u_{2}(x, t) \\
& =\frac{1}{2661120}\left[-\frac{11}{5}\left(-173+56 t^{2}\right) x^{10} C_{1}^{2}\right. \\
& -\frac{43}{4} x^{12} C_{1}^{2}+66 x^{8}-15 C_{1} \\
& +\left(-15 C_{1}+36 t^{2}\right) C_{1}^{2}-15 C_{2} \\
& -665280 t^{2} x^{2}\left(C_{1}+C_{2}+C_{1}^{2}\right)+110880 x^{4} \\
& \cdot\left(\left(-1+t^{2}\right) C_{1}+\left(-1+2 t^{2}\right) C_{1}^{2}\right. \\
& \left.+\left(-1+t^{2}\right) C_{2}\right) \\
& -3696 x^{6}\left(\left(-7+3 t^{2}\right) C_{1}+\left(-14+11 t^{2}\right) C_{1}^{2}\right. \\
& \left.\left.+\left(-7+3 t^{2}\right) C_{2}\right)\right]
\end{aligned}
$$

Third-Order Problem. Consider

$$
\begin{aligned}
& \frac{\partial^{2} u_{3}(x, t)}{\partial x^{2}} \\
& =\left[\left(1+C_{1}\right) \frac{\partial^{2} u_{2}(x, t)}{\partial x^{2}}+C_{2} \frac{\partial^{2} u_{1}(x, t)}{\partial x^{2}}+C_{3} \frac{\partial^{2} u_{0}(x, t)}{\partial x^{2}}\right. \\
& -C_{1} u_{0}(x, t) \frac{\partial^{2} u_{2}(x, t)}{\partial t^{2}}-C_{1} u_{2}(x, t) \frac{\partial^{2} u_{0}(x, t)}{\partial t^{2}} \\
& -C_{1} u_{1}(x, t) \frac{\partial^{2} u_{1}(x, t)}{\partial t^{2}}-C_{2} u_{0}(x, t) \frac{\partial^{2} u_{1}(x, t)}{\partial t^{2}} \\
& -C_{2} u_{1}(x, t) \frac{\partial^{2} u_{0}(x, t)}{\partial t^{2}}-C_{3} u_{0}(x, t) \frac{\partial^{2} u_{0}(x, t)}{\partial t^{2}} \\
& \left.+C_{3}\left(\frac{x^{2}}{2}+\frac{t^{2}}{2}-1\right)\right], \\
& u_{3}(0, t)=0, \quad \frac{\partial}{\partial x} u_{3}(0, t)=0 .
\end{aligned}
$$


Its solution is

$$
\begin{aligned}
& u_{3}(x, t) \\
& =\frac{1}{319334400} \\
& \cdot\left[-12 x^{2}\left(3 5 2 t ^ { 2 } \left(37800-12600 x^{2}\right.\right.\right. \\
& \left.+2310 x^{4}-135 x^{6}+7 x^{8}\right) \\
& +x^{2}\left(2217600-1034880 x^{2}+108240 x^{4}\right. \\
& \left.\left.-7612 x^{6}+215 x^{8}\right)\right) C_{1}^{2} \\
& +\left(-13305600 x^{4}+9313920 x^{6}\right. \\
& -1591920 x^{8}+195800 x^{10}-12586 x^{12} \\
& \left.+\frac{49221}{91} x^{14}-\frac{2867}{240} x^{16}-\frac{8}{13} x^{2} t^{2}\right) \\
& \cdot\left(129729600-64864800 x^{4}-1904760 x^{6}\right. \\
& \left.+166452 x^{8}-6604 x^{10}+231 x^{12}\right) C_{1}^{3} \\
& -12 x^{2} C_{1}\left(6 6 0 \left(168 t^{2}\left(60-10 x^{2}+x^{4}\right)\right.\right. \\
& \left.+x^{2}\left(1680-392 x^{2}+15 x^{4}\right)\right) \\
& +\left(3 5 2 t ^ { 2 } \left(37800-12600 x^{2}\right.\right. \\
& \left.+2310 x^{4}-135 x^{6}+7 x^{8}\right) \\
& +x^{2}\left(2217600-1034880 x^{2}\right. \\
& +108240 x^{4}-7612 x^{6} \\
& \left.\left.+215 x^{8}\right)\right) C_{2} \text { ) } \\
& -7920 x^{2}\left(168 t^{2}\left(60-10 x^{2}+x^{4}\right)\right. \\
& \left.+x^{2}\left(1680-392 x^{2}+15 x^{4}\right)\right) \\
& \left.\cdot\left(C_{2}+C_{3}\right)\right] \text {. }
\end{aligned}
$$

Adding (20), (22), (24), and (26), we obtain

$$
\begin{aligned}
u\left(x, t, C_{1}, C_{2}, C_{3}\right)= & u_{0}(x, t)+u_{1}\left(x, t, C_{1}\right) \\
& +u_{2}\left(x, t, C_{1}, C_{2}\right) .
\end{aligned}
$$

The residual can be calculated by using (14). For calculations of the constants $C_{1}, C_{2}$, and $C_{3}$, using (27) in (17) and applying the procedure mentioned in (13) and (14), we get

$$
\begin{gathered}
C_{1}=-1.0639118119872306, \\
C_{2}=-9.762978332188523 \times 10^{-4}, \\
C_{3}=1.287603572987478 \times 10^{-4}, \\
u(x, t) \\
=\left[x ^ { 2 } \left(0.5+3.12815 \times 10^{-7} x^{2}\right.\right. \\
-1.0409 \times 10^{-4} x^{4}+2.812 \times 10^{-4} x^{6} \\
-2.52425 \times 10^{-5} x^{8}+3.37375 \\
\times 10^{-5} x^{10}-2.03977 \times 10^{-6} x^{12} \\
\left.+4.50493 \times 10^{-8} x^{14}\right) \\
\times t^{2}\left(0.5+1.87689 \times 10^{-3} x^{2}\right. \\
-4.4610 \times 10^{-4} x^{4}+1.53732 \\
\times 10^{-3} x^{6}-1.38661 \times 10^{-3} x^{8} \\
+2.28978 \times 10^{-4} x^{10}-1.53259 \\
\left.\left.\times 10^{-5} x^{12}+5.3608 \times 10^{-7} x^{14}\right)\right] .
\end{gathered}
$$

The Exact solution is [2]

$$
u(x, t)=\frac{x^{2}+t^{2}}{2}
$$

and HPM solution is [2]

$$
\begin{aligned}
& u(x, t) \_ \text {HPM } \\
& =\left[\frac{t^{2}}{2}+\frac{x^{2}}{2}-\frac{x^{4}}{24}+\frac{x^{8}}{2688}+\frac{x^{6} t^{2}}{240}-\frac{327 x^{8}}{241920}\right. \\
& \left.\quad+\frac{x^{8} t^{2}}{1120}-\frac{x^{10} t^{2}}{21600}+\frac{1038 x^{10}}{3628800}-\frac{x^{12}}{107520}\right] .
\end{aligned}
$$

\section{Results and Discussions}

The formulation presented in Section 2 provides accurate solutions for the problems demonstrated in Section 3. We have used Mathematica 7 for most of our computational work. In Table 1 and Figures 1, 2, 3, we have compared the OHAM results with the results obtained by HPM and Exact for various values of $x$ and $t$ at spatial domain $[0,1]$ for Table 1 and at different values of $x$ and fixed value of $t=1$ for Figures 1-3. In Table 2, we have presented absolute errors at different values of $x$ and $t$. Figure 4 presents the residual at a spatial domain $[0,1]$ at $t=1$. The convergence of OHAM is presented in Figure 5 at $t=1$. 


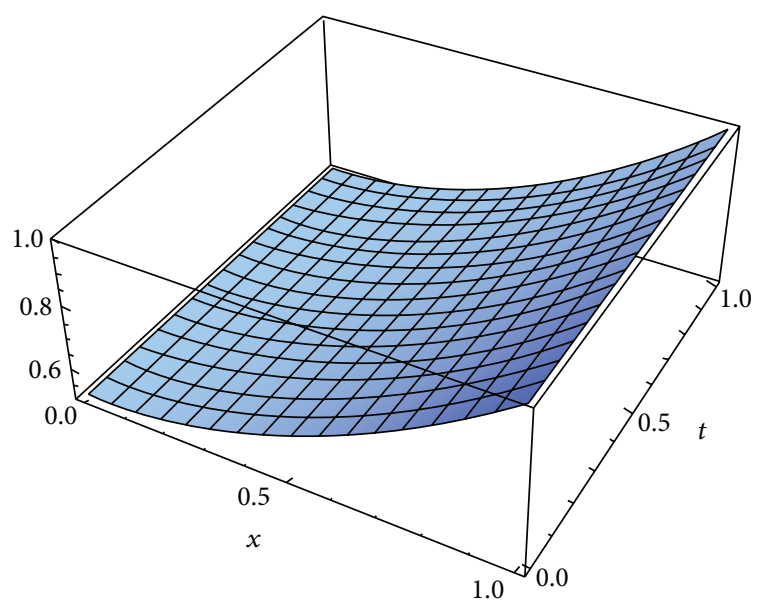

FigUre 1: 3D plot for the OHAM solution at $t=1$.

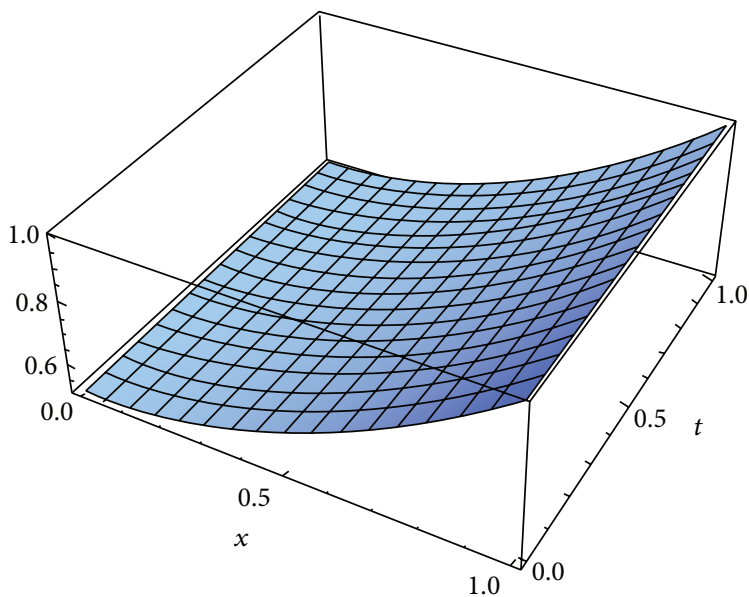

Figure 2: 3D plot for the Exact solution at $t=1$.

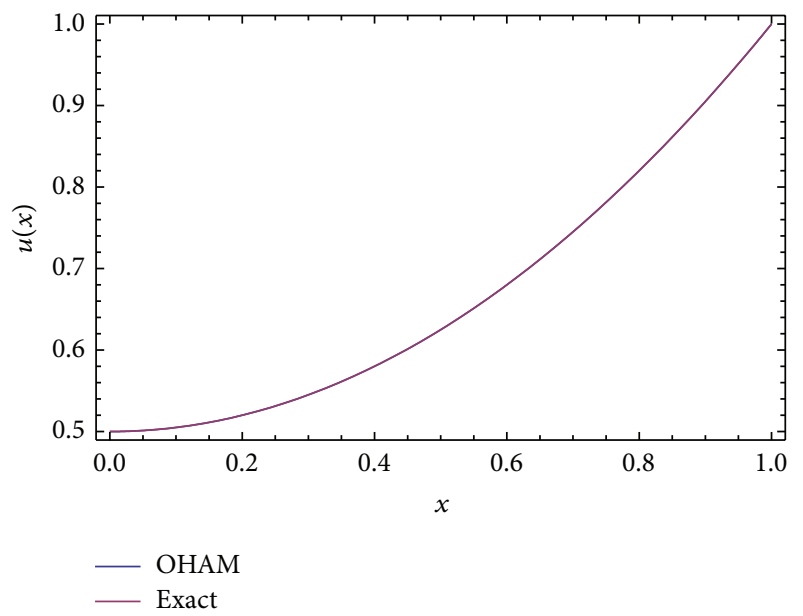

FIgUre 3: 2D plot for the OHAM and Exact solutions at $t=1$.
TABLE 1: Comparison of Exact, HPM, and OHAM solutions for different values of $x$ and $t$.

\begin{tabular}{lcccc}
\hline$x$ & $t$ & Exact solution & HPM solution & OHAM solution \\
\hline 0 & 0 & 0.00000 & 0.000000 & 0.00000 \\
0.062 & 0.162 & 0.015044 & 0.015044 & 0.015044 \\
0.156 & 0.156 & 0.024336 & 0.024336 & 0.024336 \\
0.225 & 0.128 & 0.033504 & 0.033505 & 0.033504 \\
0.187 & 0.275 & 0.055297 & 0.055297 & 0.055297 \\
0.281 & 0.281 & 0.078961 & 0.078961 & 0.0789608 \\
0.343 & 0.343 & 0.117649 & 0.117650 & 0.117648 \\
0.350 & 0.263 & 0.095834 & 0.095835 & 0.095834 \\
0.468 & 0.468 & 0.219024 & 0.219032 & 0.219022 \\
0.369 & 0.384 & 0.141801 & 0.141810 & 0.141808 \\
0.350 & 0.870 & 0.439700 & 0.439706 & 0.439697 \\
0.539 & 0.403 & 0.226465 & 0.226476 & 0.226463 \\
0.780 & 0.111 & 0.310360 & 0.310263 & 0.310358 \\
0.593 & 0.593 & 0.351649 & 0.351704 & 0.351647 \\
0.620 & 0.685 & 0.426813 & 0.426913 & 0.426808 \\
0.656 & 0.656 & 0.430336 & 0.430462 & 0.430332 \\
0.781 & 0.781 & 0.609961 & 0.610499 & 0.609963 \\
0.843 & 0.843 & 0.710649 & 0.711668 & 0.710652 \\
0.968 & 0.968 & 0.937024 & 0.940295 & 0.936958 \\
0.975 & 0.692 & 0.714744 & 0.716206 & 0.714690 \\
1.000 & 1.000 & 1.000000 & 1.004310 & 0.999877 \\
\hline & & & &
\end{tabular}

TABLE 2: Comparison of absolute errors of HPM and OHAM solutions for different values of $x$ and $t$.

\begin{tabular}{lccc}
\hline$x$ & $t$ & $E^{*}$ & $E^{* *}$ \\
\hline 0 & 0 & 0.00000000 & 0.00000000 \\
0.062 & 0.162 & $6.003 \times 10^{-12}$ & $1.74057 \times 10^{-12}$ \\
0.156 & 0.156 & $1.128 \times 10^{-9}$ & $6.00903 \times 10^{-9}$ \\
0.225 & 0.128 & $2.613 \times 10^{-9}$ & $2.49951 \times 10^{-9}$ \\
0.187 & 0.275 & $1.213 \times 10^{-8}$ & $3.5136 \times 10^{-8}$ \\
0.281 & 0.281 & $1.275 \times 10^{-7}$ & $1.91487 \times 10^{-7}$ \\
0.343 & 0.343 & $6.370 \times 10^{-7}$ & $5.53487 \times 10^{-7}$ \\
0.350 & 0.263 & $3.309 \times 10^{-7}$ & $4.03006 \times 10^{-7}$ \\
0.468 & 0.468 & $7.922 \times 10^{-7}$ & $2.28841 \times 10^{-7}$ \\
0.369 & 0.384 & $1.273 \times 10^{-6}$ & $8.50245 \times 10^{-7}$ \\
0.350 & 0.870 & $5.736 \times 10^{-6}$ & $3.11566 \times 10^{-6}$ \\
0.539 & 0.403 & $1.122 \times 10^{-6}$ & $2.45830 \times 10^{-6}$ \\
0.780 & 0.111 & $9.873 \times 10^{-5}$ & $4.00013 \times 10^{-6}$ \\
0.593 & 0.593 & $5.497 \times 10^{-5}$ & $4.1745 \times 10^{-6}$ \\
0.620 & 0.685 & $1.010 \times 10^{-4}$ & $4.68453 \times 10^{-6}$ \\
0.656 & 0.656 & $1.263 \times 10^{-4}$ & $3.64289 \times 10^{-6}$ \\
0.781 & 0.781 & $5.378 \times 10^{-4}$ & $2.2877 \times 10^{-6}$ \\
0.843 & 0.843 & $1.019 \times 10^{-3}$ & $2.6668 \times 10^{-6}$ \\
0.968 & 0.968 & $3.271 \times 10^{-3}$ & $6.56401 \times 10^{-5}$ \\
0.975 & 0.692 & $1.461 \times 10^{-3}$ & $5.41072 \times 10^{-5}$ \\
1.000 & 1.000 & $4.310 \times 10^{-3}$ & $1.22591 \times 10^{-4}$ \\
\hline$E^{*}=1 H \mathrm{EM}$ & $\mathrm{E}$ &
\end{tabular}

$E^{*}=\mid \mathrm{HPM}-$ Exact $\left|, E^{* *}=\right| \mathrm{OHAM}-$ Exact $\mid$. 


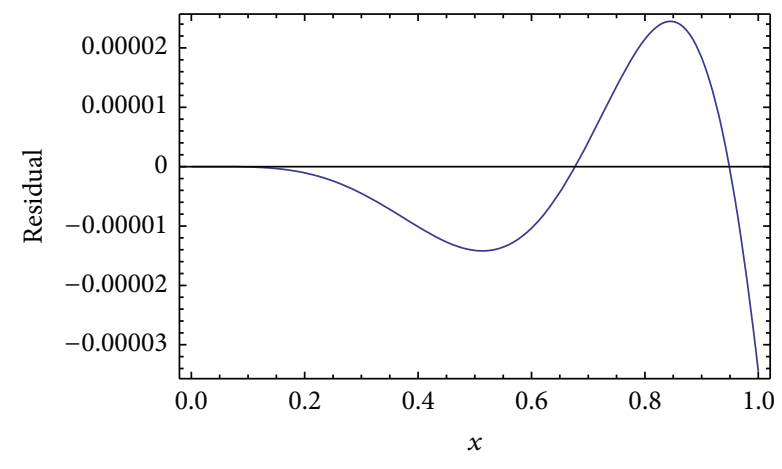

Figure 4: 2D plot for the residual of OHAM at $t=1$.

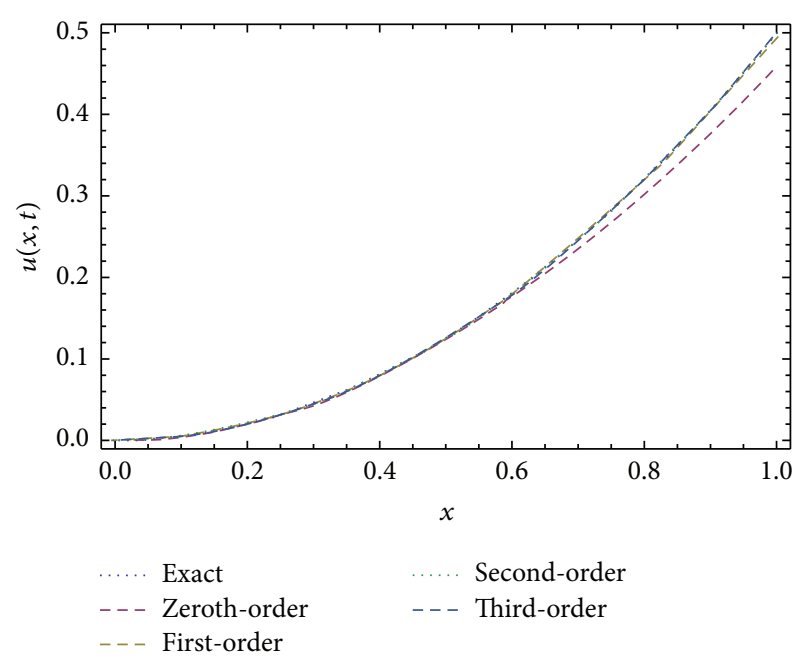

FIGURE 5: 2D plot for the convergence of orders of OHAM solution at $t=1$.

\section{Conclusion}

In this paper, we studied the two-dimensional nonlinear wave equation. We have used the OHAM to approximate the solution of the titled problem. It is clear from the present work that OHAM can successfully be applied to nonlinear phenomena like the one we had. The obtained results are accurate which shows the effectiveness and validity of the proposed method. It is observed that OHAM is simpler in applicability and more convenient to control the convergence and involve less computational work.

\section{Conflict of Interests}

The authors declare that there is no conflict of interests regarding the publication of this paper.

\section{References}

[1] A. A. Hemeda, "Variational iteration method for solving wave equation," Computers \& Mathematics with Applications, vol. 56, no. 8, pp. 1948-1953, 2008.
[2] M. Ghasemi, M. T. Kajani, and A. Davari, "Numerical solution of two-dimensional nonlinear differential equation by homotopy perturbation method," Applied Mathematics and Computation, vol. 189, no. 1, pp. 341-345, 2007.

[3] J. D. Cole, Perturbation Methods in Applied Mathematics, Blaisdell Publishing, Waltham, Mass, USA, 1968.

[4] A. H. Nayfeh and D. T. Mook, Nonlinear Oscillations, John Wiley \& Sons, New York, NY, USA, 1979.

[5] S. J. Laio, The proposed homotopy analysis technique for the solution of nonlinear problems [Ph.D. thesis], Shanghai Jiao Tong University, 1992.

[6] S. J. Liao, "A kind of approximate solution technique which does not depend upon small parameters," International Journal of Non-Linear Mechanics, vol. 32, pp. 815-822, 1997.

[7] S. J. Liao, "A new branch of solutions of boundary-layer flows over a stretching flat plate," International Journal of Heat and Mass Transfer, vol. 49, pp. 2529-2539, 2005.

[8] S.-J. Liao, "A new branch of solutions of boundary-layer flows over a permeable stretching plate," International Journal of NonLinear Mechanics, vol. 42, no. 6, pp. 819-830, 2007.

[9] J.-H. He, "Homotopy perturbation technique," Computer Methods in Applied Mechanics and Engineering, vol. 178, no. 3-4, pp. 257-262, 1999.

[10] J.-H. He, "Homotopy perturbation method for bifurcation of nonlinear problems," International Journal of Nonlinear Sciences and Numerical Simulation, vol. 6, no. 2, pp. 207-208, 2005.

[11] J.-H. He, "Asymptotology by homotopy perturbation method," Applied Mathematics and Computation, vol. 156, no. 3, pp. 591596, 2004.

[12] J.-H. He, "Application of homotopy perturbation method to nonlinear wave equations," Chaos, Solitons and Fractals, vol. 26, no. 3, pp. 695-700, 2005.

[13] J.-H. He, "The homotopy perturbation method for nonlinear oscillators with discontinuities," Applied Mathematics and Computation, vol. 151, no. 1, pp. 287-292, 2004.

[14] D. D. Ganji and A. Sadighi, "Application of He's homotopyperturbation method to nonlinear coupled systems of reactiondiffusion equations," International Journal of Nonlinear Sciences and Numerical Simulation, vol. 7, no. 4, pp. 411-418, 2006.

[15] D. D. Ganji and A. Rajabi, "Assessment of homotopy-perturbation and perturbation methods in heat radiation equations," International Communications in Heat and Mass Transfer, vol. 33, no. 3, pp. 391-400, 2006.

[16] D. D. Ganji, M. Nourollahi, and E. Mohseni, "Application of He's methods to nonlinear chemistry problems," Computers \& Mathematics with Applications, vol. 54, no. 7-8, pp. 1122-1132, 2007.

[17] G. Domairry and N. Nadim, "Assessment of homotopy analysis method and homotopy perturbation method in non-linear heat transfer equation," International Communications in Heat and Mass Transfer, vol. 35, no. 1, pp. 93-102, 2008.

[18] S. X. Liang and D. J. Jeffrey, "Comparison of homotopy analysis method and homotopy perturbation method through an evolution equation," Communications in Nonlinear Science and Numerical Simulation, vol. 14, no. 12, pp. 4057-4064, 2009.

[19] V. Marinca, N. Herişanu, and I. Nemeş, "Optimal homotopy asymptotic method with application to thin film flow," Central European Journal of Physics, vol. 6, no. 3, pp. 648-653, 2008.

[20] V. Marinca and N. Herişanu, "Accurate analytical solutions to oscillators with discontinuities and fractional-power restoring force by means of the optimal homotopy asymptotic method," 
Computers \& Mathematics with Applications, vol. 60, no. 6, pp. 1607-1615, 2010.

[21] V. Marinca and N. Herişanu, "Determination of periodic solutions for the motion of a particle on a rotating parabola by means of the optimal homotopy asymptotic method," Journal of Sound and Vibration, vol. 329, no. 9, pp. 1450-1459, 2010.

[22] H. Ullah, S. Islam, M. Idrees, and M. Arif, "Solution of boundary layer problems with heat transfer by optimal homotopy asymptotic method," Abstract and Applied Analysis, vol. 2013, 10 pages, 2013.

[23] R. Nawaz, H. Ullah, S. Islam, and M. Idrees, "Application of optimal homotopy asymptotic method to Burger equations," Journal of Applied Mathematics, vol. 2013, Article ID 387478, 8 pages, 2013.

[24] H. Ullah, S. Islam, M. Idrees, and R. Nawaz, "Application of optimal homotopy asymptotic method to doubly wave solutions of the coupled Drinfel'd-Sokolov-Wilson equations," Mathematical Problems in Engineering, vol. 2013, Article ID 362816, 8 pages, 2013.

[25] H. Ullah, S. Islam, M. Idrees, and M. Fiza, "Solution of the differential-difference equations by optimal homotopy asymptotic method," Abstract and Applied Analysis, vol. 2014, Article ID 520467, 7 pages, 2014.

[26] H. Ullah, S. Islam, I. Khan, S. Shardian, M. Fiza, and T. N. Abdelhameed, "Approximate solution of the generalized coupled Hirota-Satsuma coupled KdV equation by extended optimal homotopy asymptotic method," MAGNT Research Report, vol. 2, no. 7, pp. 3022-3036, 2014. 


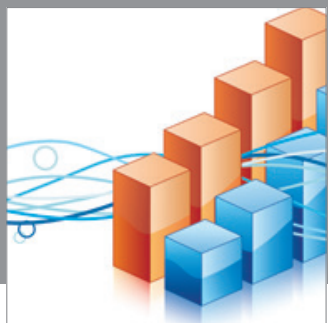

Advances in

Operations Research

mansans

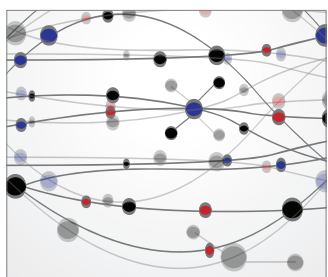

The Scientific World Journal
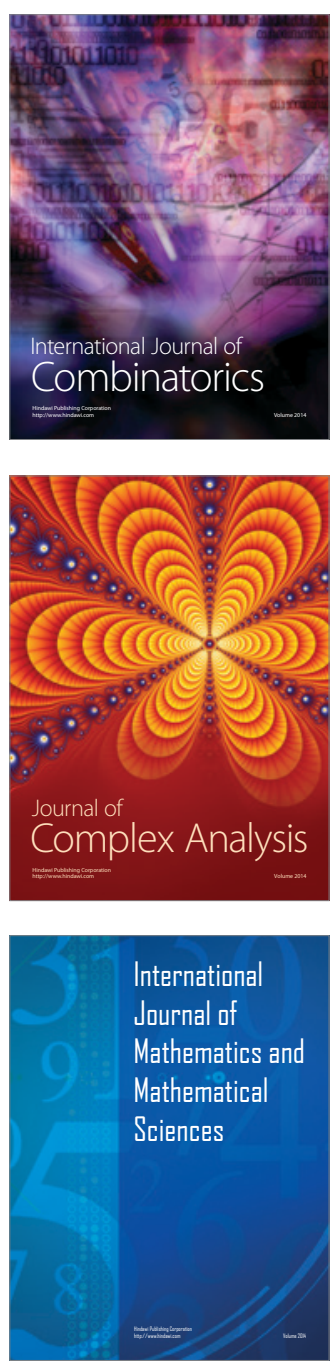
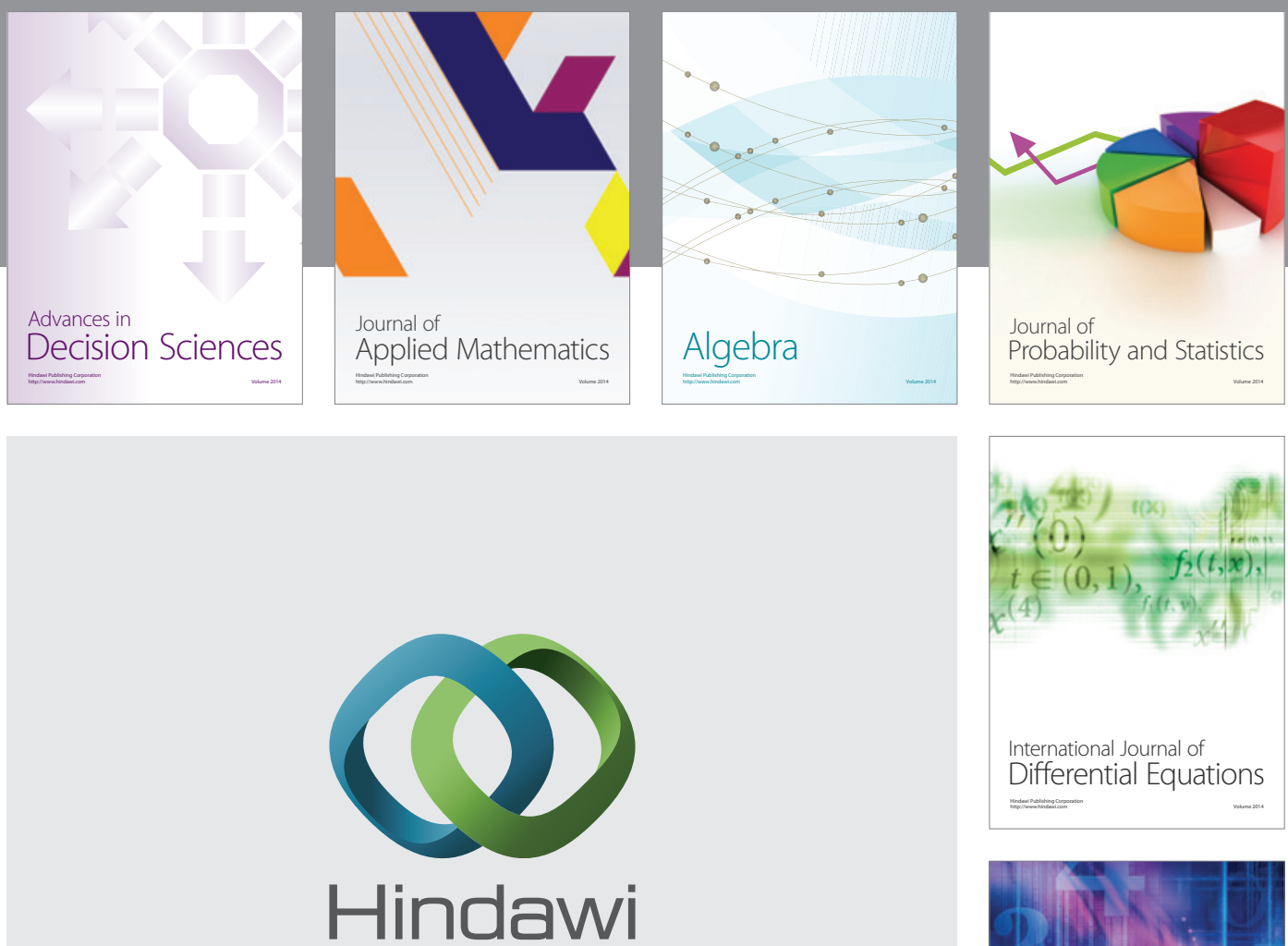

Submit your manuscripts at http://www.hindawi.com
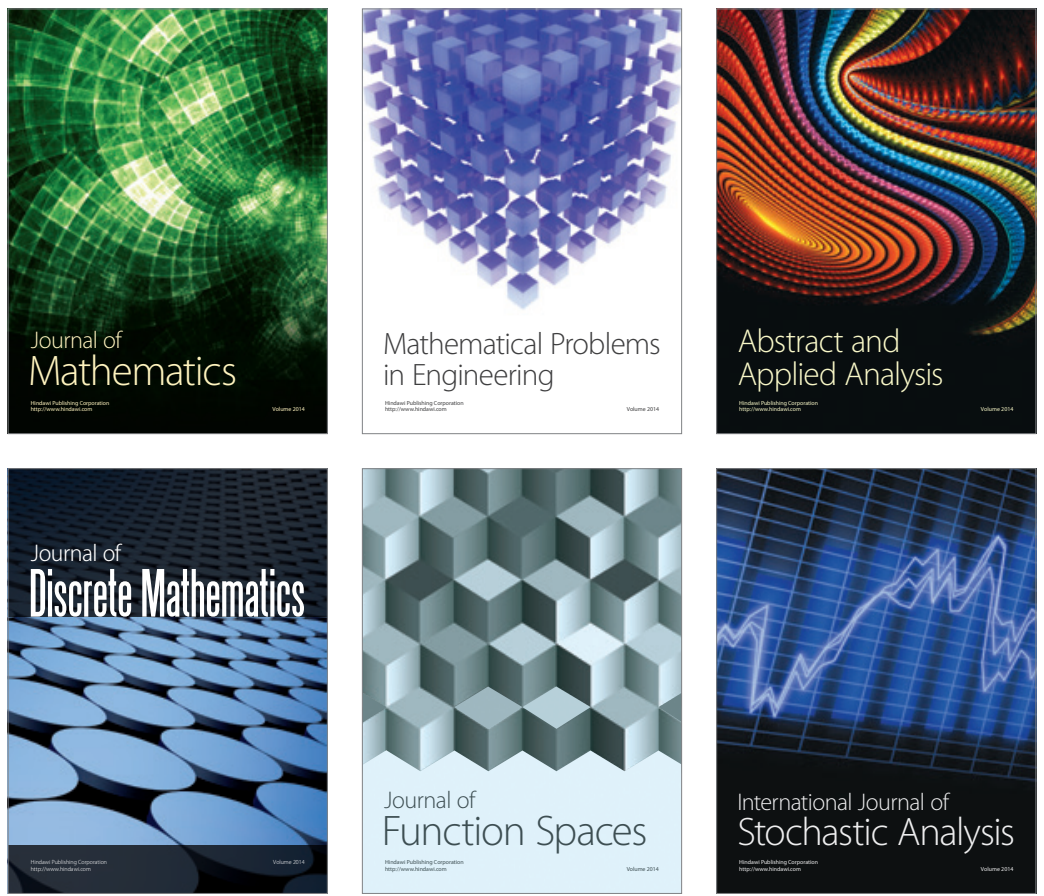

Journal of

Function Spaces

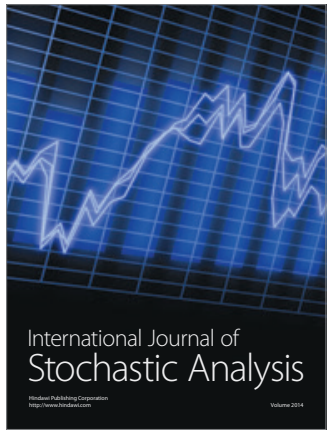

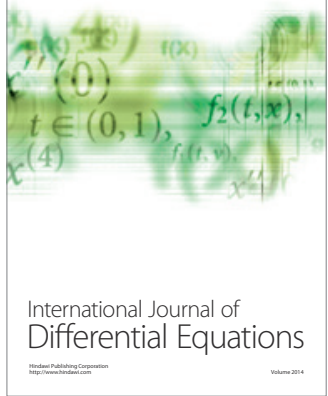
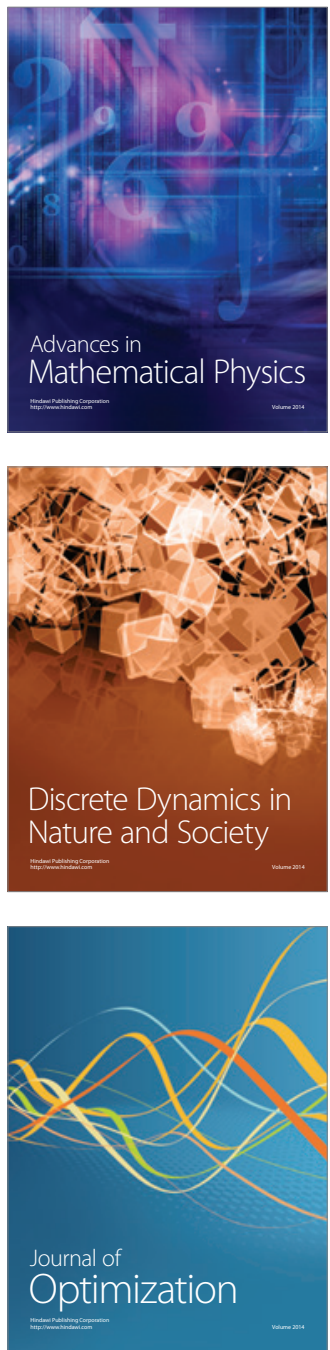